Cetlerr, H. C., and M. C. Cutler. 1948. Studies on the structure of the maize plant. Amn. Missouri Bot. Gard. 35: 301-316.

Curter, E. 1956. The experimental induction of buds from leaf primordia in Dryopteris aristata Druce. Ann. Bot., n. s., 20: 143-165.

Cialinat, W. C. 1961. Corn's cvolution and its significance for breding. Econ. Bot. 15: 320-325.

(iernert, B. 1912. A now subspocies of Zea mays Lim. Amer. Nat. 46: 616-622.

HADORs, $\mathrm{E}$. 1962. Fractionating the fruit fly. Sci. Amor. 206: $100-110$.

Hestop-Harrison, J. 1961. The experimental control of sexuality and infloresence structure in Zea mays $\mathbf{L}$. Proc. Linn. Soc. Lond. 192: 108-123.

Kемpток, J. H. 1921. Inheritanee of ramose infloresrence in maize. U. S. Dept. Agric. Bull. 971.

Kiessembach, T. A. 1949. The structure and reproduction of corn. Univ. Nebraska Coll. Agric. Bull. 161.

I.AlBengayer, R. A. 1949. The viscular anatomy of the eight-rowed ear and tassel of Ciolden Bantam Sweet corn. Amer. Jour. I3ot. 36: 2:36-244

Mangersdonf, P. C. 1945. The origin and nature of the car of maize. Bot. Mus. Leafl., Harvard Univ. 12: $33.3-8.8$.

Nelsox, (). E., and S. N. Postlethwait. 1954. Variation in atypical growth in a maize mutant. Amer. Jour. Bot. 41: 739-748.
Nickensox, N. H. 1954. Morphological analysis of the maize ear. Amer. Jour. Bot. 41:87-92.

- —, AND 'T. N. EMblekr. 1960. Studies involving sustained tratment of maize with gibberellic acid. I. Further notes on responses of rares. Ann. Missouri Bot. (iard. 47:227-242.

Revess, R. G. 1946. Methods for studying the maize car. Bot. (iaz. 10\%: 425

- 1950. Morphology of the car and tassel of maize. Amer. Jour. Bot. 37: 697-704.

Stein, (). L., Anj) 1), M. Strafenskn. 1959. The activity of $\mathrm{x}$-rayed apical meristems: a genetic and morphogenetic analysis in Zea mays. Zeitseh. Vererbungslehre $90: 4 \times 3-502$.

Sussix, I. 1962. Plant morphogenesis. This is life, essays in modem hiolory. Holt, Rinehart and Winston, New York.

WardiaW, C. W. 1952. Phylogeny and morphogenesis. Maemillan \& Co., Itd., London.

-.. 1959. Methods in plant morphogenesis. Jour. Jinn. Soc. Lond. 56: 15t-159.

- - 1960. The inception of shoot organization. Phytomorphology 10: 107-110.

Weatherwax, P. 1917 . The development of the spikelet of Zea mays. Bull. 'Torrey Bot. Club 44: 48:3-496.

-. 1935. The phylogeny of $Z e a$ mays. Amer. Midland Nat. 16: 1-71.

Wetmors, R. H. 1959. Morphogenesis in plants-a new approach. Amer. Sci. 47:326-340.

Amer. Jour. Bot. 51(3): 243-252. 1964.

\title{
MORPHOLOGY AND GENETICS OF A PERIODIC COLONIAL MUTANT OF NEUROSPORA CRASSA ${ }^{1}$
}

\author{
Alfred S. Sussman, Robert J. Lowry, and Thomas Durkee \\ Department of Botany, University of Michigan, Am Arbor, Michigan
}

\section{A B S T R A C T}

\begin{abstract}
A mutant of strain 69-1113a of Neurospora crassa, which shows periodic growth upon both complete and minimal media, was named "clock," and some of the morphological and genetic differences between this mutant and the "patch" and "wild" strains were investigated. In contrast to the uniform growth of "wild," the "clock" mutant produces a series of bands formed by cymelike aggregations of hyphase which become progressively more dense and finally mark the end (front) of a growth band. A new growth band is formed by a number of hyphae which grow out as in "wild" strains and dichotomize and form new cymes which again become progressively more dense and finally form a new front. It is shown that "clock" continues its rhythmic growth when cultured in continuous darkness. Some "wild" strains were induced to grow periodically on appropriate media. A medium containing equal quantities of sorbose and sucrose caused strain 65-811A (a "wild") to produce the "patch" type growth. Random isolation, as well as ordered isolation, of ascospores following a cross between "wild" and "clock" show a 1:1 segregation indicating that "clock" differs from "wild" by a single gene.
\end{abstract}

Rнчтнміс phenomena in plants are manifested in a variety of ways and may well be ubiquitous

1 Received for publication May 29, 1963

The authors would like to acknowledge the support of the Rackham Fund of the University of Michigan and the United States Public Health Service, National Institutes of Health, Grant-in-Aid RG-9887.
(Bünning, 1958). The more conspicuous of these are those displayed by fungi among which "fairy rings" represent the best-known example (Shantz and Piemeisel, 1917; Ramsbottom, 1923). Other instances where fruiting occurs with a definite periodicity include Penicillium sp. (Sagromsky, 1952), Pilobolus sphaerosporus (Bruce, Weight, 

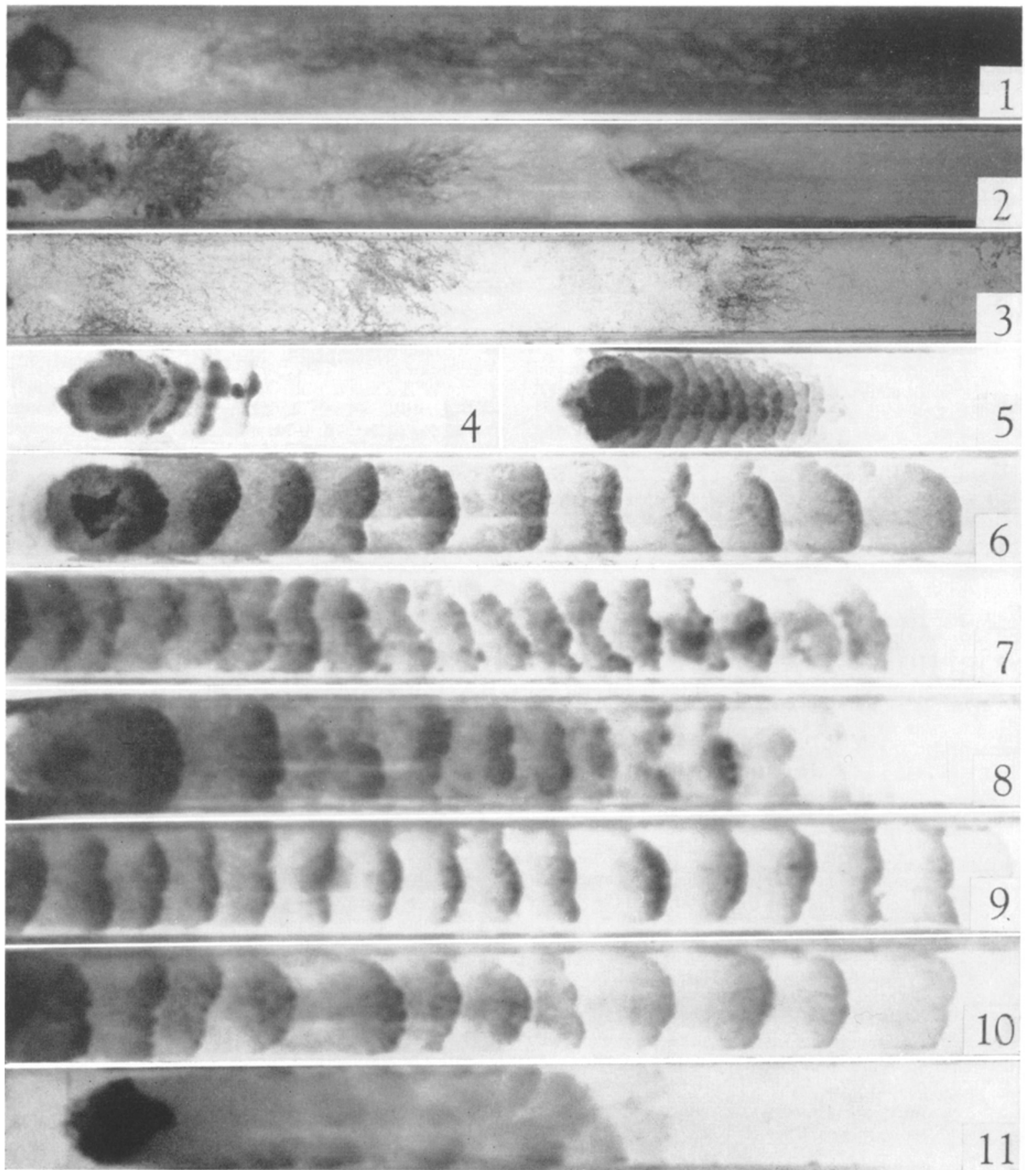

Fig. 1-11.-Appearance of various strains of Neurospora crassa in growth tubes.-Fig. 1. Strain 65-811A grown on "complete" medium.-Fig. 2. Strain 65-811A grown on "minimal" medium plus $0.8 \%$ sorbose and $0.8 \%$ sucrose.Fig. 3. Strain 491 (proline-deficient) on Brandt's medium.-Fig. 4. Strain 65-811A grown on Schaeffer's medium.Fig. 5. A small "clock" grown on "complete" medium.-Fig. 6. A large "clock" on "complete" medium.-Fig. 7-11. The strains were all grown on "complete" medium.-Fig. 7. "Clock" with ronsistent cyele sizes.-Fig. 8. "Clock" showing decreasing cycle sizes.-Fig. 9. "Clock" showing increasing cycle sizes.-Fig. 10. "Clock" showing cycles of varying size in no consistent pattern,-Fig. 11. An aperiodic variant of "clock." All figures approx. $\times 1.2$. 
and P'ittendrigh, 1960), the "patch" mutant of Neurospora crassa (Brandt, 1953; Pittendrigh et al., 1959; Stadler, 1959), and several additional cases cited in the review by Jerebzoff (1961). Discharge of spores also may be rhythmic in fungi like Pilobus sphaerosporus (Schmidle, 1951), Sphaerobolus stellatus (Friederichsen and Fngel, 1960), and Sordaria fimicola (Ingold, 1958). Moreover, periodic alteration in the branching patterns of hyphae has been found to explain zonations in the growth of Ascobolus immersus (Chevaugeon, 1959 a) and, recently, even luminescence in Basidiomycetes has been shown to be rhythmic, according to Berliner (1961). The wide distribution of these rhythms in fungi and the diverse physiological processes affected suggest that they play an important role in these organisms.

Therefore, when a variant which formed distinct hands in a regular periodicity appeared in one of our cultures of Neurospora crassa, we decided to study it further. Our hope was that the amenability of this organism to genetic experimentation and its simple growth requirements would provide an opportunity to explore the mechani:m and role of a biological rhythm throweh a varicty of approaches.

The experiments reported here are designed to outline the range of variants that have arisen from this periodi: variant. In addition, we have provided a detailed description of the branching patterns of "wild" and periodic strains in order that the groundwork be laid for our future research on the determination of morphology in Neurospora. Finally, the genetic difference between "wild" and certain periodic variants will be discussed

MA'TERIALS AND ME'THODS-The original "clock" strain of Neurospora was isolated while one of uss (A.S.) was sereening strain 69-1113a ( $\mathrm{T}^{\mathrm{s}}$ ) for mutants at the $\mathrm{T}$ (tyrosinase)-locus, through the use of Schaeffer's medium. This variant was picked because it blackened very rapidly on this medium (Fig. 28) so that it appeared to be a "super-producer" of tyrosinase. Upon transfer to "complete" medium, periodic growth was observed to occur, and the strain was retained for further analysis.

Media that were used included "minimal" (Vogel, 1956), "complete" (Ryan, 1950), the crossing medium of Westergaard and Mitchell (1947), and Brandt's medium (Brandt, 1953). In addition, the modified Schaeffer's medium (Sohaeffer, 1953) used was made up as follows: Vogel's (1956) $50 \times$ concentrate (low-sulf ur), 20 $\mathrm{ml}$; L-tyrosine, $0.181 \mathrm{~g}$; yeast extract (Difco), 5.0 $\mathrm{g}$; tryptose (Difco), $2.5 \mathrm{~g}$; sucrose, $1.0 \mathrm{~g}$; sorbose, $8.0 \mathrm{~g}$; agar, $15.0 \mathrm{~g}$; distilled water to $1,000 \mathrm{ml}$.

Cultures were maintained at $24 \mathrm{C}$ unless otherwise noted. A container of water was kept in the incubators in order to keep the humidity high, but otherwise no attempt was made to regulate humidity.

Microscopic observation of cultures was accomplished in several ways. These included the inoculation of a thin film of agar on a microscope slide which was incubated in a damp chamber. Before observation, a cover slip was placed over the culture. The underside of the lid of a plastic Petri dish also served as support for a thin film of agar. Water in the bottom kept the culture from drying. The mycelium was observed through the top of the dish. Finally, a thin layer of agar was added to the bottom of a plastic Cooper tissue culture dish $(60 \times 15 \mathrm{~mm})$ available from Falcon Plastics, Inc. In this case, observation was made through the top of the dish.

Dark-field lighting was arranged through the use of a circular fluorescent illuminator:

Results-Gross morphology of "clock"-In contrast to the "wild" $(65-811 \mathrm{~A})$ strain which shows the usual spreading type of mycelium on "minimal" or "complete" medium in growth tubes (Fig. 1), "clock" strains show a banded type of growth which varies in the size and regularity of the bands (lig. 5-11). Figure 5 illustrates a small "clock," Fig. 6 a large one, and Fig. 7 one of medium size like the original "clock" isolate. Figure 7 also illustrates consistent band width, whereas the strain in Fïg. 8 produces smaller bands with age and the strain in Fig. 9 produces larger bands with age. The strain in Fig. 10 produces large and small bands in no regular pattern. Figure 11 illustrates an asynchronous strain, the geneties and morphology of which will be discussed elsewhere. Several colonial, but aperiodic, variants of "clock," like that seen in Fig. 34, have also been isolated. These and the other variants discussed above were obtained from backcrosses and sectors.

The "patch" mutant of Neurospora crassa, which displays a circadian rhythm in the formation of conidia, as described by Brandt (1953) and by Pittendrigh et al. (1959), is illustrated in Fig. 3 . The "clock" strains reported here do not form conidia.

The growth of a "clock" strain across "complete" medium in a Petri dish is illustrated in liig. 12-17 by dark-field lighting and slight magnification. The first growth cycle is essentially completed in ligg. 12. In l'ig. 13, two hours later, peripheral growth has stopped and initial hyphae of the next cycle have appeared. After forward progression of the colony has stopped, considerable filling in of hyphae still occurs, especially in the first part of the cycle. The initial hyphae of the next cycle grow forward at a greater rate than hyphae in the later stages and appear similar to those of "wild" strain (Fig. 14). Fan-like aggregations of hyphae appear and become progressively more dense, finally forming the end (front) of a growth band (Fig. 15, 16). The growth period (time to complete one growth band) in the strain used for the above sequence was about $26 \mathrm{hr}$ at $22 \mathrm{C}$.

Microscopic morphology of "clock" strainsHyphae of "wild" strains of Neurospora crassa grow monopodially (Fig. 18). The mycelium con- 

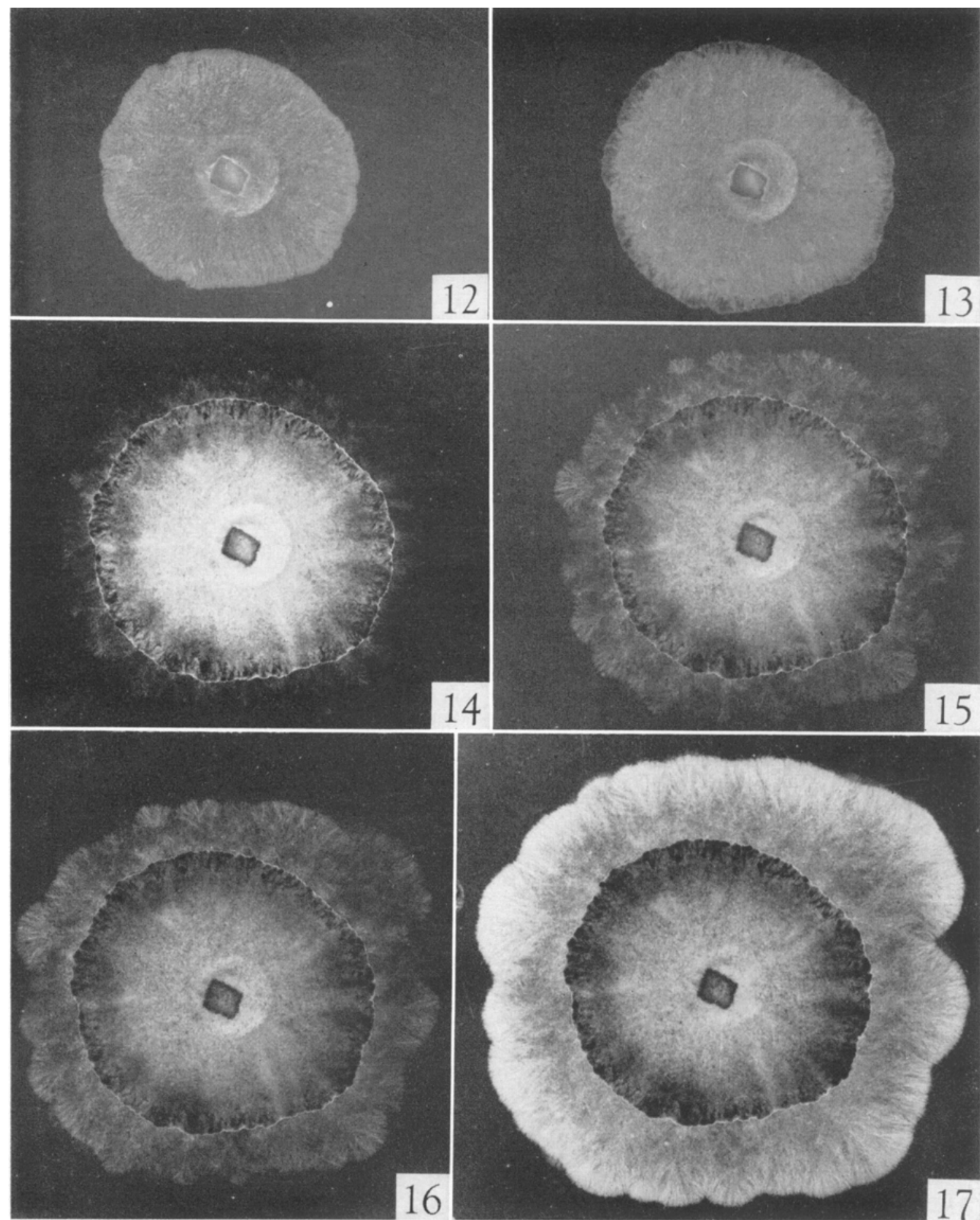

Fig. 12-17.-Dark-field study of growth of a "clock" colony - Fig. 12. Stage of growth about 2 hr before completion of first cycle. Photographed at 3:30 pM.-Fig. 13. End of first cycle. Photographed at 5:30 pM.-Fig. 14. Early stage in second cycle. Note development of hyphae around periphery of colony. Photographed at 3:30 Am.-Fig. 15. Later stage in development of second cycle. Note fan-like aggregates of hyphae at periphery of colony. Photographed at 7:30 AM.Fig. 16. Stage in colony development when rate of forward progression is being reduced. Photographed at 9:30 AM.Fig. 17. Colony about $4 \mathrm{hr}$ before completion of second cycle. Photographed at 3:30 pM of day following start of observations. Colony grown in "complete" medium at $25 \mathrm{C}$. $\times 1.7$. 


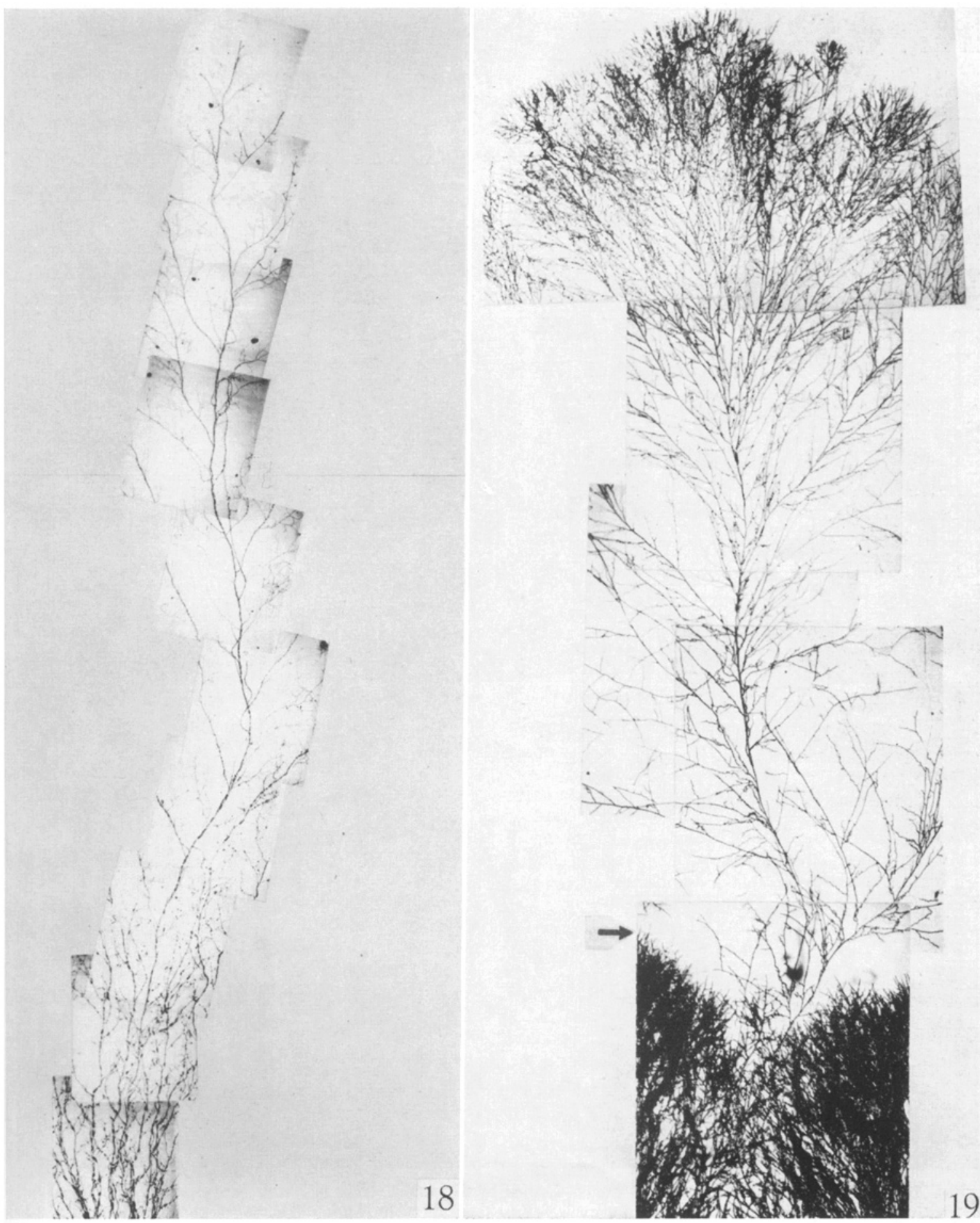

Fig. 1\$-19.-Composite photomicrographs of mycelium of "wild" and "clock" strains of Neurospora crassa.-Fig. 18. Colony of strain 69-1113a grown on "complete" medium at $27 \mathrm{C}$ for $12 \mathrm{hr}$ and photographed in sections which were reassembled in this composite illustration. Note the monopodial branching pattern of this "wild" strain. $\times 10 .-$ Fig. 19 . Colony of "clock" grown on "complete" medium and photographed and reassembled as in Fig. 18. The dense zone of hyphae designated by the arrow at the bottom identifies the end of the first cycle of growth. $\times 25$. 

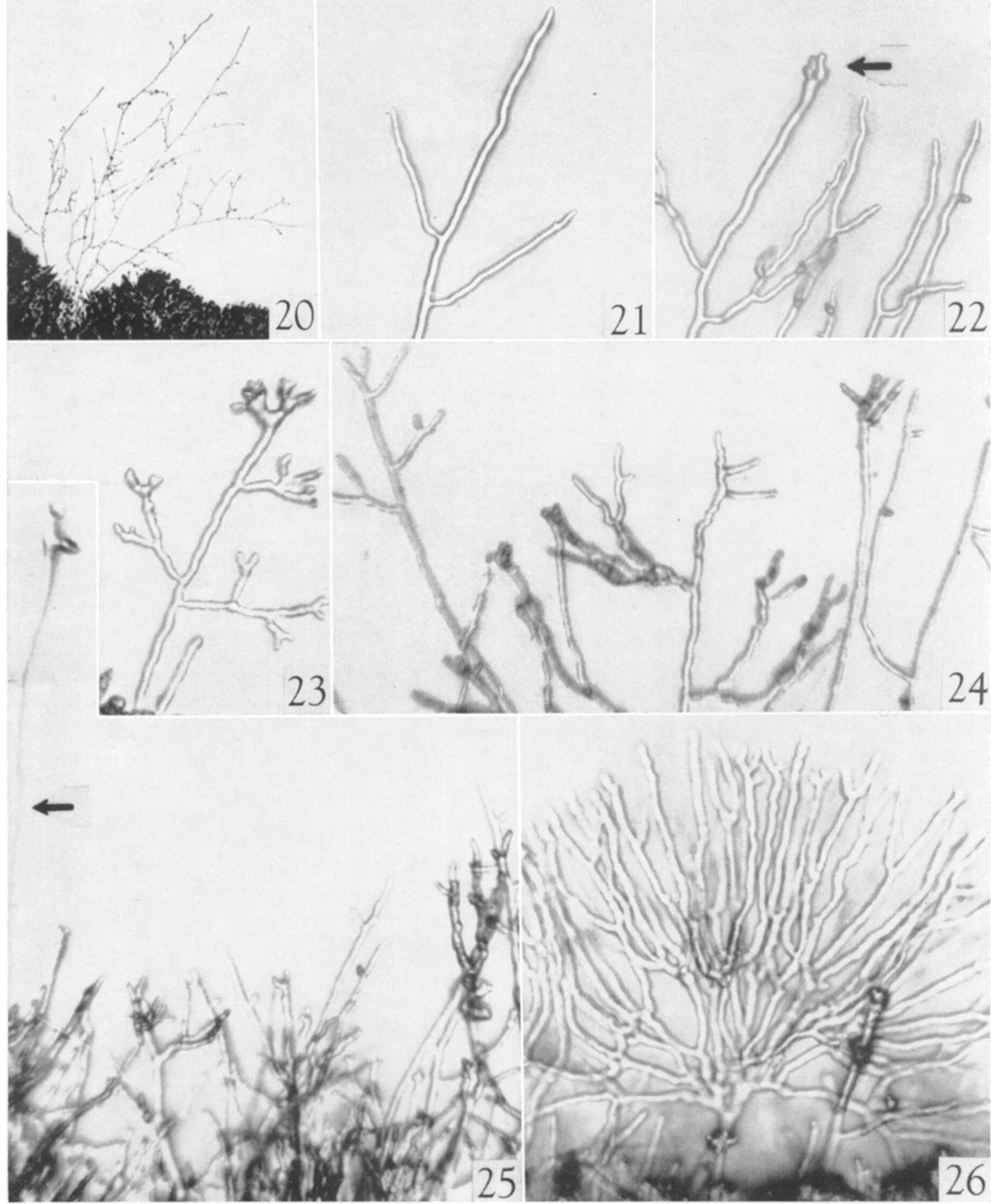

Fig. 20-26. Microscopic development of a "ycle formed by a "clock" strain of Neurospora crassa.-Fig. 20. Hyphac originating from the periphery of the preceding cycle-Fig. 21. Type of hypha found initiating the development of a new cycle.-Fig. 22. A stage in hyphal formation following the formation of initial hyphac. Note the tendency of the apex of the hypha at the arrow to dichotomize.-Fig. 23. Further development of dichotomizing hyphac.-Fig. 24. Appearance of hyphae at the periphery of a colony near the end of a cycle. At this time the primary hyphae have stopped their forward progression.-Fig. 25. Colony near the end of a cycle. A hypha may be seen initiating the next cycle at the arrow.-Fig. 26. Fan of hyphae formed by the precocious initiation of growth after the end of a cycle. "Complete" medium was used for all cultures which were maintained at 25C. Fig. 20 approx. $\times 50 ;$ Fig. 21-26 approx. $\times 300$. 
ТАвLE 1. Ability of Schaeffer's medium to elicit cyclic growih in "wild" strains of Neurospora crassa and $N$. tetrasperma. Cultures were inoculated in Petri dishes which were maintained at $25 \mathrm{C}^{\prime}$

\begin{tabular}{|c|c|}
\hline Strain number & $\begin{array}{l}\text { Cyclic growth: } \\
\text { Present }(+) \text { or } \\
\text { absent }(-)\end{array}$ \\
\hline $\begin{array}{l}\text { Neurospora crassa: } \\
69-1113 \mathrm{a} \\
\text { 6.5-811A } \\
89601 \mathrm{~A} \text { inos } \\
113-15 \mathrm{~A} \\
913 \mathrm{~s} \text { A } \\
5297 \mathrm{a} \text { (Lmorson) } \\
4 \mathrm{AR} \\
69-113-\mathrm{R}-10\end{array}$ & $\begin{array}{l}+ \\
+ \\
+ \\
+ \\
+ \\
+ \\
+ \\
+\end{array}$ \\
\hline $\begin{array}{l}\text { N.tetrasperma: } \\
394.5\end{array}$ & + \\
\hline $\begin{array}{l}\text { N. crassa: } \\
89601 \mathrm{a} \\
8269-6 \mathrm{~A} \\
25 \mathrm{a} \\
1 \mathrm{~A}\end{array}$ & $\begin{array}{l}- \\
- \\
- \\
-\end{array}$ \\
\hline
\end{tabular}

sists of main, radial hyphae and smaller primary and secondary branches. Branching begins about $15-20 \mu$ from the hyphal tip. The mycelium of "clock" strains is strikingly different (F"ig. 19). from the dense mass of hyphae marking the end of the growth band, a new cycle originates in a few hyphae that branch monopodially and differ initially from those of "wild" only in the larger diameter of the primary and secondary branches (Fig. 20, 21). As the cycle progresses, branching becomes more dichotomous, the rate of forward progression decreases, and the number of branches per unit length of hypha increases (Fig. 22, 23). A number of primary branches become main hyphac (Fig. 19) and contribute to the formation of the front (Fig. 24). Several hours before the front stops its forward progression marking the end of a cycle, one or more hyphae may grow beyond the front at any point. These hyphae may stop growing after an hour or so and form fan-like aggregates (likg. 15, 16, 26), or they may continue to grow, forming the initial hyphae of the next (ycle (lïg. 25).

Effect of light-Brandt (1953) has shown that zonation in "patch" occurs when germination and growth take place in total darkness. Therefore, similar experiments were performed with "clock" and it was found that the rhythm was maintained during a series of bi-weekly transfers over a period of 4 months. The only exposure to light was at the time of transfer. In strong continuous light, however, the rhythm was found to decay.

Induction of cyclic growth in "wild" strains of Neurospora-Several "wild" strains were inoculated on Petri dishes containing Schaeffer's medium and some were found to grow periodically
(Table 1). A few such colonies (Fig. 4, 30-32) can be compared with the appearance of "wild" on agar' medium (Fig. 29). A dark pigment formed in the bands which was not generally distributed in the colony or medium; however, when "clock" strains were grown on Schaeffer's medium, intense pigmentation occurred in both colony and medium (Fig. 28). It was found that a "minimal" medium containing $0.8 \%$ sorbose and $0.1 \%$ suerose also elicited rhythmic growth in "wild" strains and it thus appears likely that the sorbose in Srhaeffer's medium is responsible for induring the rhythmicity. less pigment was formed in the sorbose medium probably because fewer phenolic; substrates of tyrosinase are present than in Schaeffer's medium.

Not all "wild" strains exhibited rhythmic growth on Schaeffer's medium (Table 1, Fig. 33, 35). Since these strains grew colonially, the lack of rhythm could not be ascribed to insensitivity to sorbose as a paramorphic agent.

Comparison of "wild," "cloch" and "patch" strains-It was found that strain 65-811A ("wild"), grown on a "minimal" medium to which $0.8 \%$ each of sorbose and sucrose had been added, formed patches of conidiophores in a rhythmic manner (Fig. 2) closely resembling the "patch" mutant (lig. 3) deseribed by Brandt (1953). Strain 69-1113a ("wild") failed to produce conidiophores in a consistent way when grown on the above medium.

Stadler" (1959) suggested that the ability to "escape" on sorbose is associated with the "patch" mutation; therefore, to further compare "clock" and "patch," strains of the former were grown on "minimal" medium containing a ratio of sorbose to sucrose of $8: 1$, at 2 levels, including 0.8 and $8.0 \%$ of sorbose. Clock strains remained colonial with a much-reduced band width (Fig. 27).

Genelics of "clock" strains-Crosses were made between "clock" and "wild" strains on Westergaard's medium (Westergaard and Mitchell, 1947). In random samples of spores (96-309 isolates per cross) from 17 different crosses between "clock" and "wild" siblings from original "clock" mutant X "wild," 15 crosses gave segregation of "clock" and "wild" in the ratio of 1:1 $\left(\mathrm{P}-<0.10 \chi^{2}\right.$ test); segregation in the remaining 2 crosses deviated significantly from $1: 1(\mathrm{P}-$ $<0.01)$. Since segregation in most crosses was $1: 1$, it is very probable that "clock" represents a

TABL: 2. Analysis of ordered asci from the cross between "clock" strains and strain 85-311A

\begin{tabular}{ccc}
\hline \hline Cruss & \multicolumn{2}{c}{ Type of segregation } \\
\cline { 2 - 3 } & 1st division & 2nd division \\
\hline $1 \mathrm{C} \times 85-311 \mathrm{~A}$ & 9 & 13 \\
$16 \mathrm{~g} \times 85-311 \mathrm{~A}$ & 4 & 16 \\
$15 \mathrm{a} \times 85-311 \mathrm{~A}$ & 8 & 12 \\
\hline
\end{tabular}



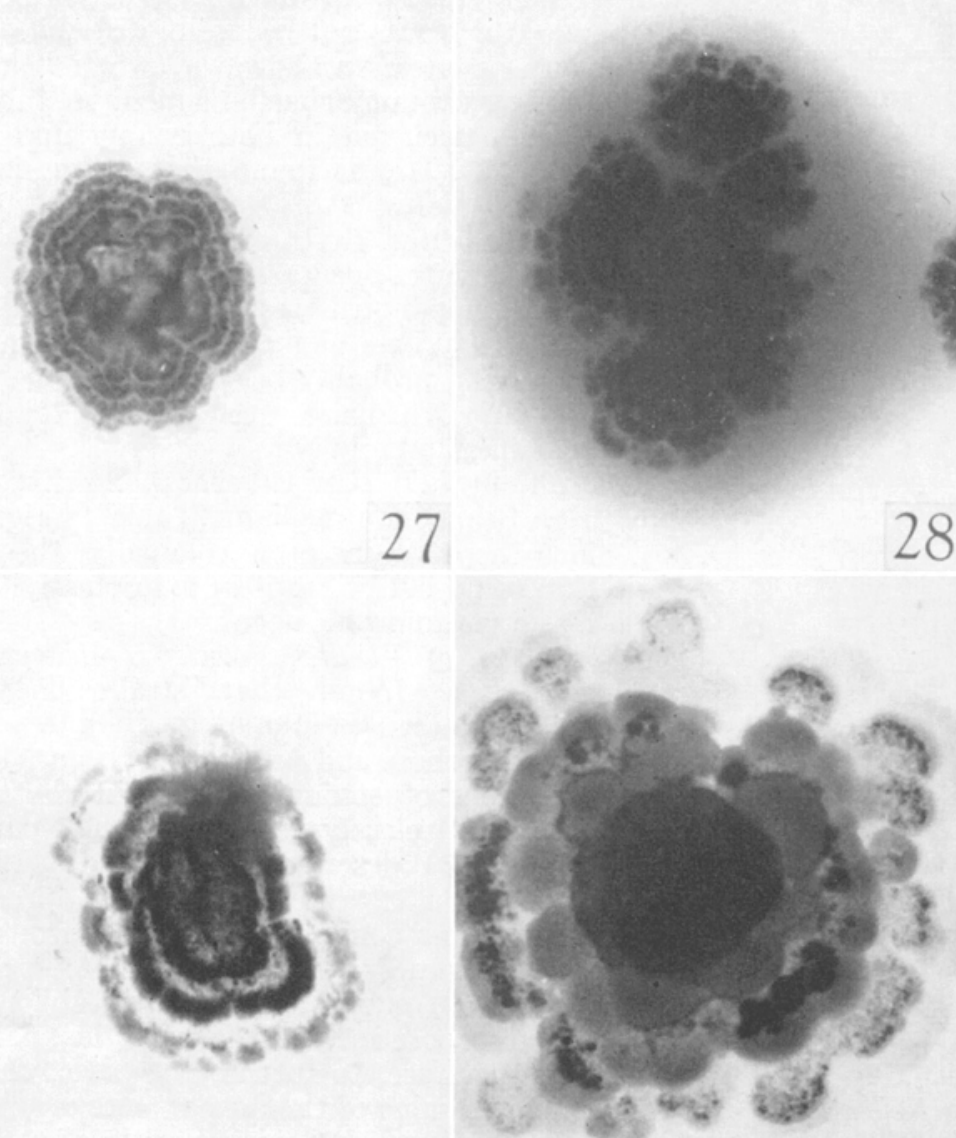

30
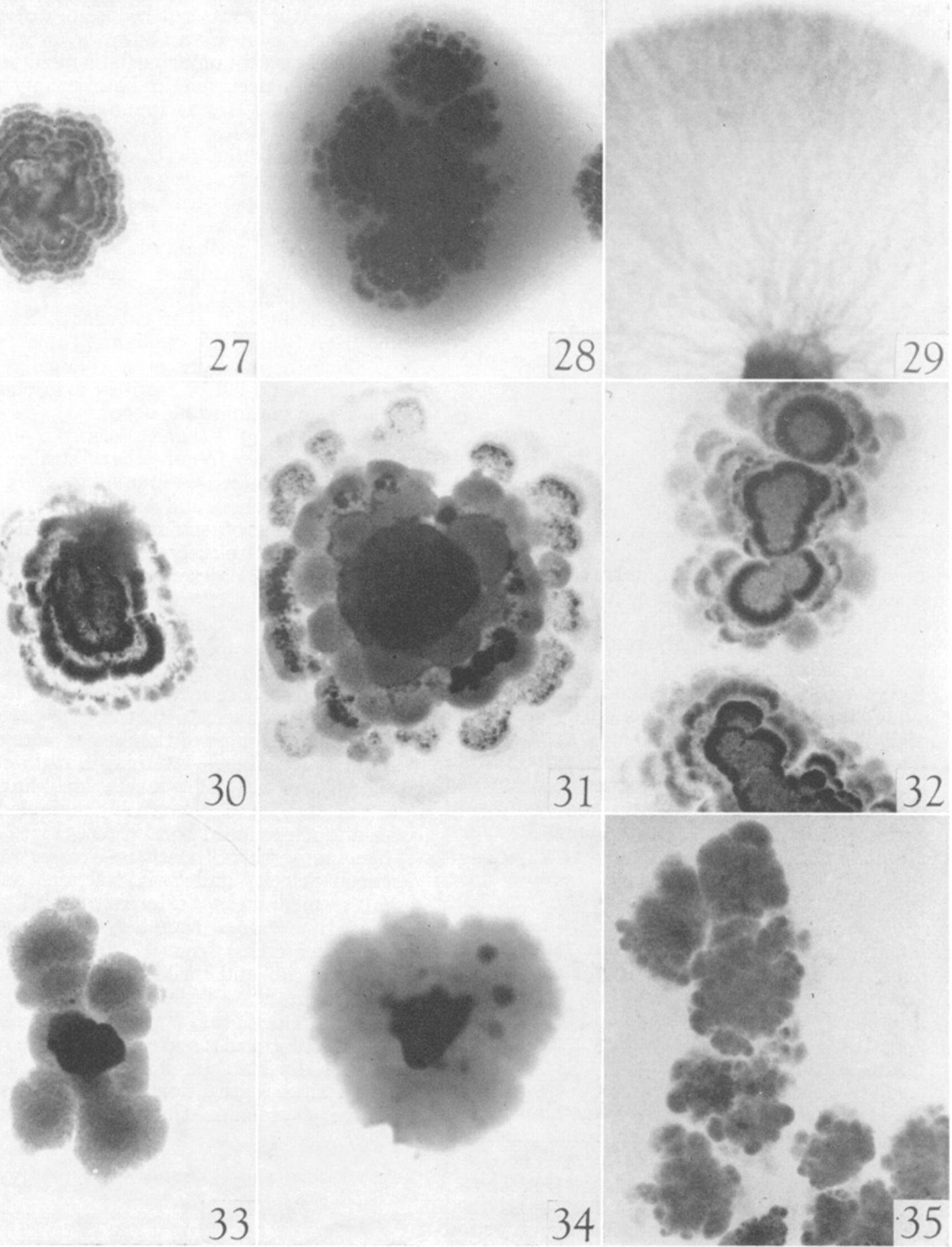

Fig. 27-35. Appearance of colonies of "clock" and "wild" strains of Neurospora on various media.-Fig. 27. "Clock" grown on "minimal" medium plus $8 \%$ sorbose and 1\% sucrose.-Fig. 28. "Clock" grown on Schaeffer's medium.-Fig. 29. Strain 69-113a grown on "complete"medium.-Fig. 30. Strain 69-113-R-10 grown on Schaeffer's medium.-Fig. 31. $N$. tetrasperma grown on Schaeffer's medium.-Fig. 32. Strain 65-811A grown on Schaeffer's medium.-Fig. 33. Strain 1269-6a grown on Schaeffer's medium.-Fig. 34. A revertant from "clock" grown on "complete" medium.-Fig. 35. Strain 89601a grown on Schaeffer's medium. All figures approx. $\times 2$. 
mutation at a single locus. This conclusion is strongly supported by the fact that ordered ascospore isolation from 62 asei gave the $1: 1$ ratio (Table 2 ).

Discusion - The growth of many filamentous fungi, like some Basidiomycetes (Butler, 1961) and imperfect fungi (Robertson, 1958; P'irt and (allow, 1959), is characterized by the extension, at regular intervals, of lateral hyphae which usually form well below the apex. As the fungus progresses over the medium, there is very little variation in the density of the mycelium. This patteres of growth is to be contrasted with that of the "clock" mutants of Neurospora in which the monopodial type of growth described above is maintained for only a short time at the beginning of a cycle. Thereafter, the hyphae branch increasingly until the growth is almost entirely dichotomous, at which time forward progression ceases. As a result, a zone is formed due to the relatively sparse mycclium formed at the beginning of the growth cycle, followed by the denser mycelium formed during the time of dichotomous growth. The regular succession of such zones distinguishes the growth of "clock" from that of "wild" strains. Very similar differences appear to occur between "wild" strains of Ascobolus immersus and the "wavy" ("vague") mutant which was isolated by Chevaugeon (1959a).

The appearance of mutants in Neurospora which demonstrate periodicity in their growth ("clock") and conidiation ("patch") raises questions about the significance of the rhythms to the organisms. For example, are such rhythms induced merely as aberrations associated with ultraviolet irradiation? That this is not the case is shown by the fact that untreated "wild" strains of Neurospora can be induced to form "clocks" or "patches" in media containing certain ratios of sorbose to sucrose. Morcover, the similarity in the period of these rhy thms suggests that the same underlying rhythm is inherent in many strains of Neurospora, although its manifestations may vary depending upon the morphologieal and physiological processes to which it may be coupled. Another question that may be asked concerns the role of such rhythms in the organism, but too little is known of it in nature to make such speculations profitable at this time. Moreover, the failure of sorbose to induce rhythms in some of the "wild" strains casts doubt on their ubiquity in Neurospora. However, the wide distribution of rhythms in fungi (Jerebzoff, 1961) suggests a selective advantage.

Chemicals other than sorbose have been found to induce rhythms in certain fungi. Thus, a mixture of different sugars, including maltose, glucose, sucrose, fructose and raffinose, was found to reproduce the inductive effect of malt extract upon the growth rhythm in Alternaria tenuis when it was added to agar containing potato extract
(Jerchzoff, 1961). However, it should be pointed out that the concentration of the pure sugars needed to produce the effect was higher than that of the sugars found in malt extract. Glucose also has becn shown to induce a persistent growth rhythm in Leptosphaeria michotii in the dark, according to Jerebzoff and Isacoste (1962). Amino acids in a potato extract medium substitutes for yeast extract in eliciting zonations in Aspergillus ochraceus (Jerebzoff, 1961). That a balanse between the concentration of certain salts and other nutrients is important in the establishment of such rhythms has recently been proposed (Jerebzoff', 1962; Chevaugeon, 1959b).

Physical factors which induce rhythms in the fungi include light in Monilia fructicola (Sagromsky, 1959), various speries of I'enicillium (Jerebzoff, 1961), Trichothecium roseum (Sagromsky, 1956), Pilobolus sphacrosporus (Schmidle, 1951 ) and othors. By contrast, both "clock" and "patch" will grow periodically even in total darkness, therchy demonstrating a "free-running" rhythm.

\section{LITERATURE CITLD}

Berlixer, M. 1). 1961. Studies in fungal luminesenence. Mycologia 53: 81-90.

BrandT, W. H. 1953. Zonation in a prolincless strain of Nenospora. Mvcologia 45: 194-20s.

Bruce, V. G., F. Weight, and C. S. Pittendrigh. 1960. Resetting the sporulation rhythm in Pilobolus with short light flashes of high intensity. Science 131: $728-730$

BünNing, E. 1958. Die physiologische Uhr. Springer Verlag, Berlin, Germany. 105 p.

Buther, (i. M. 1961. Growth of hyphal branching systems in Coprinus disseminatus. Ann. Bot. 25: $341-352$.

Chevauglon, J. 1959a. La zonation du thalle, phénomène périodique autonome chez l'Ascobolus immersus. Compt. Rend. Acad. Sei. (Paris) 248: 1381-13\%1

—_- 1959b. Influence de quelques substances sur la manifestation du rhy thme de croissance chez l'Ascobolus immersus. Compt. Rend. Acad. Sci. (Paris) 249: $1703-1705$.

Friederichisen, I., $\Lambda \times D$ H. ENare. 1960. Der $A$ bschussrhythmus der Fruchtkörper von Sphaerobolus stellatus (Thode) Pers. Planta 55:313-326.

Ixgold, C. T. 19is. On light-stimulated spore dis(harge in Sordaria. Ann. Bot. (Lond.), N. S., 22: $129-1355$.

JERleBzofF, S. 1961. Étude de phénomènes périodiques chez quelquess champignons. Thèses, Univ. de Toulouse.

_- 1962. Importance d'équilibres nutritionnels sur la manifestation du rhythme endogène de zonations chez Alternaria tenuis auct. Compt. Rend. Acad. Sci. 254: $2062-2063$.

——, ANd L. Lacoste. 1962. Existence de deux rythmes endogènes de zonations chez Leplosphaeria michotii (West.) Sacc. Compt. Rend. Acad. Sci. (Paris) 254: 1483-1485.

Pirt, S. J., And D. S. Callow. 1959. Continuous-flow culture of the filamentous mould Penicillium chrysoge- 
num and the control of its morphology. Nature (Lond.) 184: 307-310

Pittendrigh, C. S., V. G. Bruce, N. S. Rosknwlici, and M. L. Rubin. 1959. Growth patterns in Neurospora. Niture (Lond.) 184: 169-170.

Ramsвotтom, J. 1923. Handbook of the larger British fungi. British Museum, London, England. $222 \mathrm{p}$.

Rober'son, N. F. 1958. Observations on the effect of water on the hyphal apices of Fusarium oxysporum. Ann. Bot. (Lond.), N. S., 22: 159-173.

RYAN, F. T. 1950. Selected methods of Neurospora genetics, p. 51-75. In R. Cierard, [cd.], Methods in medical research. Vol. 3. Year Book Publishers, Inc., Chicago.

SAGROMSKY, H. 1952. Der Einflusz des Lichtes auf die rhythmische Konidienbildung von Penicillium. Flora 139: 300-313.

- 1956. Zur lichtinduzierten Ringbildung bei Pilzen (III). Biol. Zentralbl. 75: 38:5-397.

- 1959. Kur lichtinduzierten Ringbildung ( $V$ )
Nachklingen der Rhythmik bei Sclerotinia fructicola (Wint.) Rehm. Biol. Zentralhl. 78: 589-597.

Sichaefrer, P. 1953. A black mutant of Neurospora crassa. Mode of action of the mutant allele and action of light. Arch. Biochem. Biophys. 47:359.

Scmmone, A. 1951. Die Tagesperiodizitit der asexuellen Reproduktion von Pilobolus sphaerosporus. Arch. Mikrobiol. 16: $80-100$.

Shant\%, H. L., añd R. I. Piembisier. 1917. Fungus fairy rings in eastern Colorado and their effect on vegetation. Jour. Agrie. Ros. 11: 191-246.

Stabler, D. R. 1959. Growth patterns in Neurospora. (ienetic control of a cyclic growth pattern in Neurospora. Nature (Lond.) 184: 170-171.

VoGes, H. J. 1956. A convenient growth medium for Neurospora (Medium N). Microbial (inet. Bull. 13: $42-43$.

Westergatrd, M., axd H. K. Mitchell. 1947. Neurospora: V. A synthetic medium favoring sexual reproduction. Amer. Jour. Bot. 34: 573-577. 